\title{
The effect of sulfur on the solubilities of highly siderophile elements (HSEs) in silicate melt
}

ZHIJIE HUANG, IAN H. CAMPBELL AND HUGH O'NEILL

Australian National University

Presenting Author: zhijie.huang1@anu.edu.au

Highly siderophile elements (HSEs; Ru, Rh, Pd, Os, Ir, Pt, Re, and $\mathrm{Au}$ ) are remarkable tracers of many geological processes. Sulfur is a minor but important element in magmas, and the HSEs have a high affinity to sulfur. However, the influence of sulfur on the solubilities of HSEs in magmas is controversial.

We have investigated the effect of sulfur on the solubilities of HSEs in a synthetic basaltic silicate melt in equilibrium with $\mathrm{Au}$, $\mathrm{Pd}$ and $\mathrm{Au}-\mathrm{Pd}$ alloy at $1300{ }^{\circ} \mathrm{C}$ in a 1-atm furnace. $\mathrm{Au}$ and $\mathrm{Pd}$ were studied in preference to other HSEs because Pd is expected to be the most chalcophile [1], whereas, the affinity of $\mathrm{Au}$ is expected to be lower [2]. A strategy of long duration experiment was carried out to suppress the formation of nano-nuggets and was tested in the sulfur-free experiment. Sulfur fugacity was varied at constant oxygen fugacity between QFM-2 and QFM0.8 and was held below sulfide saturation. Run products were quenched to glass and analyzed for major elements and $\mathrm{S}$ content by EMPA, and Au and Pd by LA-ICP-MS.

Our preliminary results show that there is a significant improvement in nugget reduction in the long experiment (7-day) compared with the short experiment (8-hour and 2-day). The positive correlation between oxygen fugacity and solubilities of HSEs are confirmed for oxygen fugacities between QFM-3 and $\mathrm{QFM}+2$. The solubility of $\mathrm{Au}$ is enhanced by increasing the sulfur fugacity and the sulfur content in the melt by up to a factor of 2. The solubility of Pd, however, decreases with increasing sulfur fugacity in the sulfur-bearing experiment but is still elevated compared with the sulfur-free experiment.

We suggest that in sulfur-bearing systems, $\mathrm{S}^{2-}$ provides an extra ligand for the HSEs cations, but the effect may be orders of magnitudes less than previously thought (e.g. [3]). Our results will have profound implications for the quantitative modelling of HSEs fractionation in magmatic systems.

[1] Mungall, and Brenan, Geochimica et Cosmochimica Acta 125 (2014): 265-289. [2] Botcharnikov, et al. Nature Geoscience 4.2 (2011): 112-115. [3] Laurenz, et al. Geochimica et Cosmochimica Acta 108 (2013): 172-183. 